[This is the pre-publication version of Henry, A. (in press). Swedish or English? Migrants' experiences of the exchangeability of language resources. International Journal of Bilingual Education and Bilingualism DoI:10.1080/13670050.2015.1008979]

\title{
Swedish or English? Migrants' experiences of the exchangeability of language resources
}

\author{
Alastair Henry \\ Department of Social and Behavioural Studies, University West, Trollhättan, \\ Sweden \\ al.henry@hv.se
}

\begin{abstract}
Patterns of transmigration emerging as a consequence of globalization are creating new and complex markets for communicative resources in which languages and language varieties are differently valued (Blommaert 2010). In a Swedish context, where lingua franca English can facilitate communication but where monolingual norms prevail and Swedish is positioned as the key to 'integration', the purpose of this study is to examine English-speaking migrants’ experiences of opportunities to use Swedish and English in communication. Interviews were conducted with 14 recently-arrived migrants with English in their repertoires. Drawing on participants' experiences of language use in institutional contexts, analyses focus on the influence of value assessments, orientations to ideal-type norms, processes of selfsurveillance and the effects of discursive positionings. While migrants' language choices are understood as a consequence of structural conditions, attention is also drawn to the ways in which such choices are flexibly negotiated. Analyses shed light on participants' creative and critical capacities (Li 2011) and how, in their language choices, they evaluate, relate to and resist macro-social structures. Different varieties of English are shown to offer different
\end{abstract}


communicative opportunities and not all are equally exchangeable. Opportunities to use English also differ as a consequence of the intersections of discursive positionings.

Keywords: migration; English as a lingua franca; global English; language choices; language repertoires; Sweden

\section{Introduction}

Patterns of transmigration emerging as a consequence of globalization are creating "new and complex markets for linguistic and communicative resources” (Blommaert 2010, 3). In these new markets languages and language varieties are differently valued. While for some migrants language resources offer possibilities, others can discover theirs have little value (Blommaert 2010). The purpose of this study is, in a Swedish setting, to examine migrants' experiences of choices involving the use of English and Swedish. Because English has high prestige, is near ubiquitous in Swedish society, and because people in Sweden generally have high levels of communicative competence, it can be a valued resource. In the analyses offered here, attention is paid to varieties of English, power dynamics, and the ways that geopolitical circumstances in migrants’ places of origin can create differing opportunities to use English. Further, because in discourses of immigration Swedish is positioned as the key to 'integration', and because of the presence of monoloingual norms, ideologies and orientations (Blommaert 2010; Canagarajah 2013), analyses focus on how the choices study participants describe are influenced by value assessments, orientations to ideal-type norms, appropriateness criteria, processes of self-surveillance and perceptions of a need to position themselves in particular ways. At the same time that attention is paid to ways in which the operation of structures of power and inequality can be revealed in participants' perceptions of the exchangability of Swedish and English, focus is also directed to individual agency and how participants' accounts of language choices reveal creative and critical capacities (Li 2011). 


\section{The linguistic landscape}

\section{The near ubiquity of English}

In recent years Sweden has experienced “an overwhelming Anglicization”. A near ubiquitous presence, English can be regarded as functioning "as a second language in the Swedish daily living environment” (Cabau 2009, 134). Because of a reliance on imported media, where USand UK-produced TV programs and films are broadcast with subtitles rather than dubbed, English has long been a prominent feature in the linguistic landscape. It is encountered widely in advertising, on television, on the radio, and of course the Internet (Swedish Media Council 2013; see also Bolton and Meierkord 2013 for a recent discussion). English is a core subject in the Swedish school curriculum and not only are Swedes generally good at English emerging in two recent international surveys with the highest levels of proficiency ${ }^{\mathrm{i}}$ - but perceptions of competence are high and attitudes overwhelmingly positive ${ }^{\mathrm{ii}}$.

\section{Language policy and immigration discourses}

For migrants arriving in Sweden, language repertoires that include English can greatly facilitate initial orientation and social interaction. However there are also challenges. While, as Bolton and Meirkord (2013, 106) explain, people in Sweden “appreciate English as being helpful in interactions with those recent immigrants whose proficiency in Swedish is still too limited to allow for successful and meaningful communication”, a longer-term reliance on English can generate negative responses. As in many other European countries, immigration has become a prominent political issue, not least following the entry of the right-wing populist Swedish Democrats to parliament in 2010 (Brochmann and Hagelund 2011a, 2011b). In discourses of immigration circulating in this climate, Swedish is positioned as the 'key' to employment and 'integration', making thus the use of other languages problematic. 
Sweden has a history of liberal immigration policies. Relative to its size it has long been the country in Europe receiving the largest number of asylum-seekers. At the same time Swedish governments have pursued neoliberal policies that place increasing demands on migrants to learn Swedish as a means of facilitating integration and entry to the labour market (Rosén and Bagga-Gupta 2013; Rosén and Bagga-Gupta in press). For example, in a widely publicized position statement on the role of language in the integration of migrants, government ministers with portfolios for education, integration and equal opportunities issued a joint statement expressing the conviction that "knowledge of Swedish is decisive for being able to enter into Swedish society”, that Swedish “is the springboard into society”, and that it is “disastrous for both society and the individual” when migrants fail to learn the language (Björklund, Arnholm and Ullenhag, 2013) (author’s translation).

A number of migration-related discourses can be identified (Rosén and Bagga-Gupta 2013). These include a nationalist discourse where Swedish is positioned as the "glue" creating social cohesion and participation in society as dependent on language skills. A part of this discourse, the 2009 Language Act states that "Swedish is the main language in Sweden, i.e. the common language in society that everyone has access to and that can be used in all sectors of society” (Ministry of Culture 2009), the implication being that Swedish constitutes a "corner-stone in the construction of what it means to be a member of the nation-state of Sweden” (Rosén and Bagga-Gupta 2013, 73). The same authors identify an employability discourse where language education is positioned as the key to gaining work and becoming established on the labour market. Employability and integration discourses combine with efficiency discourses. In current policy, coercive measures are combined with incentives. While increasing demands are placed on immigrants to learn Swedish the government has, at 
the same time, provided more hours for Swedish as a second language in school and has offered monetary rewards to migrants who successfully complete language courses ahead of schedule. The central demand is that language studies should be effective, taking the minimum possible time. Consequently, many migrants with English in their repertoires and higher education backgrounds become enrolled on fast-track programs designed to bring them into the workforce as expediently as possible.

\section{Understanding language choices}

In the setting sketched out, recently arrived migrants can find themselves in situations having to navigate between Swedish and English. To understand how participants in this study experience the choices they make about whether to speak Swedish or English, two broad analytical approaches are employed. In the first of these approaches the 'sensitizing concepts' of orders of indexicality and polycentricity, developed by Blommaert (2010) in his work on the sociolinguistics of globalization, are used to understand how the deployment of language resources described by participants is situated in a larger social system. Secondly, in an attempt to understand how participants' themselves understand and rationalise the choices they make, the analysis draws on sociolinguistic concepts that, in contrast to Blommaert's theorizing, more centrally foreground individual agentic capacity. These include positioning (Pavlenko and Blackledge 2004), performativity (Pennycook 2010), voice (Canagarajah 2004) and, in particular, Li's (2011) twin concepts of creativity and criticality, where focus is directed to participants' critical appraisals of situations they identify as providing them with language-use options, and their creative use of resources in such situations.

\section{Resource deployment, sensitivity to inequalities, and the operation of power}


In contexts of social interaction arising as a consequence of globalization, focus is properly directed not to languages and language use, but to the situational deployment of language resources (Blommaert 2010; Li 2011). This involves an expansion of focus to consider not just registers and styles, but also voices. It involves the analysis of how language is spoken, when it can be spoken and to whom it matters (Blommaert 2010, 196). In the semiotic situations that develop in circumstances of super-diversity (Vertovec 2007), the investigation of patterns of resource usage requires sensitivity to inequalities and the operation of power. This, Blommaert argues, is necessary if we are to understand how the superordinate structures and mechanisms that function to generate/maintain social inequalities also determine resource deployment. The adoption of a critical stance and an awareness of the everyday impact of globalization phenomena can reveal why particular language resources are deployed in particular situations, why what counts as a valid resource in one situation might not in another, and why the same language spoken by people from different backgrounds may have a very different value. Drawing on Foucault's notion of an 'order of discourse’, Blommaert argues that there are systematic differences in the ways in which forms of language use are apprehended. Exchange economies develop in which "the values attached by some to one form of semiosis may not be granted by others” (Blommaert 2010, 38). This state of affairs the systematic ways in which, in different contexts, different languages, registers and voices are perceived and received - he describes as an order of indexicality.

The second of Blommaert's sensitizing concepts that can cast light on processes of resource deployment, polycentricity concerns the ways in which semiotic acts are oriented to different centres of power, real or imagined. In any act of communication, Blommaert explains, in addition to tailoring language use to what the individual believes are the cultural expectations of actual, physically present interlocutors, adaptation also takes place in relation to higher- 
order batteries of norms. That is, individuals orient additionally towards a larger social and cultural body of authority or 'centre', the presence of which is 'projected' through interactions with immediate addressees.

Polycentricity is important because in any situation involving the use of semiotic resources, different centres exist, each with its own particular conglomerations of norms and expectations about appropriate ways of behaving and forms of articulation. In situations that arise in contexts characterized by diversity and difference the individual is likely to be aware of the existence of multiple centres, each functioning as a referent in relation to which the selection, monitoring and appraisal of linguistic choices takes place. This means that adaptation to or violation of norms can take place at any point in time. As Blommaert (2010) explains, while sometimes this can take place intentionally, on other occasions normtransgressions may be accidental or a consequence of the impossibility of behaving in any other way.

\section{Agency, positioning, performativity and voice}

While Blommaert's concern is with the ways in which the operation of superordinate structures of power cement the material inequalities of globalization, demonstrating in his work how migrants' use of resources and orientations to the cultural expectations of interlocutors are historically and structurally conditioned, other researchers have drawn contrasting attention to the ways in which mobile resources are flexibly deployed by individuals as active agents, and how resource use is contextually negotiated. Languaging practices and the agency of individuals in interactive processes of meaning-making form central concerns in much of the sociolinguistic research carried out in multilingual contexts 
(Garcia and Li 2014) and, as a consequence of the ‘social turn’ in applied linguistics, a range of different theoretical constructs are currently employed (Canagarajah 2004).

In their development of a framework comprising different identity types, Pavlenko and Blackledge (2004) use positioning theory (Harré and van Langenhove 1999) to explain how individuals can find themselves in what they describe as a "perpetual tension between selfchosen identities and others' attempts to position them differently” (20). They explain also how, manifested in the use of language, the negotiation of identity positions takes place not only in social interaction, but also within the individual. It is through processes of negotiation, they argue, that as agentive beings, individuals are able to "resist identities that position them in undesirable ways” (27). Engaging the relationship between structure, agency and identity, and drawing on Butler’s (1990) concept of performativity, Pennycook (2003, 2010; Harissi, Otsuji and Pennycook 2012) describes how both form and meaning emerge though language use in specific social contexts. Arguing that a performativity perspective enables an understanding of identities as produced in social interaction through the use of language, he makes the point that language and identities are constantly under construction and that language practices involve both fixed and unfixed elements of language.

Like Pennycook, Canagarajah’s (2013) investigations of translingual practices have been undertaken in the context of the use of English in various settings and situations bearing the imprint of globalization. For Canagarajah it is within the micro-social contexts of everyday communication that individuals are able to demonstrate agency in resisting, modifying or negotiating macro-social structures. Explaining how rhetorical constructions of selfhood can be imposed upon or ascribed to individuals, it is, he contends, at the level of voice and in strategies of “envoicing” (Canagrajah 2013, 80) that agency to negotiate externally-ascribed 
social categories is manifested. It is in these micro contexts that a reflexive awareness of such constructions is developed and where language resources are populated with the individual's own intentions and meanings. These negotiations, he makes clear, relate both to historically defined identities (e.g. ethnicity and nationality), as well as institutional roles (e.g. teacher/student). They also take place in relation to ideological subjectivities, that is to say the individual's “positioning according to discourses such as 'responsible citizen/lazy immigrant/dependent foreigner”” (Canagarajah 2004, 267).

\section{Processes of creativity and criticality}

As Garcia and Li (2014) explain, agency is centrally implicated in mulitilinguals’ languaging practices and in the deployment of semiotic resources which derive from sets of socially constructed languages. Møller and Jørgensen (2012) similarly highlight the active employment of linguistic resources associated with different languages, while Lewis, Jones and Baker (2012) argue that, in order "to maximise understanding and performance” (643), multilinguals make situationally-determined pragmatic choices about language use. In his research on migrants’ languaging practices and resource use, Li (2011; Li and Hua 2013) emphasises the agency of the individual, arguing that the deployment of language resources are a consequence of each individual's unique cognitive processing. "Language varieties and language choices", he maintains, "are subjective and exist in the minds of the individuals. They are not simply 'brought along' by the participants of social interactions, but can be 'brought about' through specific social practices including multilingual practices” (Li 2011, 1224).

Examining the multilingual practices of Chinese youths in Britain, Li (2011) shows how the use of semiotic resources includes the full range of linguistic performances and involves not only the conveyance of information, but also the "representation of values, identities and 
relationships” (1223). As a means of shedding light on the language choices of multilinguals living in societies bearing the hallmarks of globalization, Li (2011) identifies two interlinked dimensions of the individual's languaging practices; creativity and criticality. While criticality refers to abilities to make decisions about language use based on the evaluation of social and linguistic practices, to problematize accepted conventions, and to offer reasoned responses to particular situations, creativity involves opportunities to decide whether to conform to such linguistic conventions, norms of interaction and social expectations, or whether to subvert them. As Li explains, because multilingualism involves tension, conflict, competition and difference, creativity and criticality are central features of the individual's agentic capacity to choose between the languages and language forms in their repertoires.

\section{Purpose}

In a Swedish setting where (i) English is a near ubiquitous presence, attitudes to English are positive, and where there is widespread competence, and (ii) where immigration discourses position competence in Swedish as decisive for entering society, the purpose of this study is to examine recently-arrived migrants’ experiences of making choices as to whether to speak Swedish or English. To aid this purpose the following research questions have been formulated:

(i) in what contexts do participants experience making choices about whether to speak Swedish or English?,

(ii) in what ways is the operation of structures of power and inequality revealed in participants' perceptions of the exchangability of Swedish and English?, and

(iii) how do recounted processes of choosing between Swedish and English reveal agentic capacity?

\section{Method}




\section{Participants}

Fourteen migrants with English in their repertoires participated in the study. They were enrolled on two consecutive university-provided programs offered to migrants with post upper-secondary education and CEFR B1-level skills in Swedish. The purpose of the education was to provide a fast-track into work or higher education. In addition to courses in the Swedish language, social studies courses and periods of practice were included in the programs. At the beginning of each program, the total number of enrolled students completed a questionnaire seeking information on their country of origin, reasons for coming to Sweden, language repertoires, self-assessed competence in each language, education, work history and time in Sweden. Inclusion criteria were: i) being in Sweden for less than two years, ii) selfassessed communicative competence in English ${ }^{\mathrm{iii}}$, and iii) not being a speaker of English from birth.

The participants (identified by pseudonyms), their age at the time of the interviews, gender, country of origin, language repertoire and migrant status (employing Vertovec’s (2007) taxonomy) are set out in Table 1. The participants’ professional experience included engineering, chemistry, IT, medicine, medical science, law, finance and administration, TV production, translation and education.

Table One. Study participants.

\begin{tabular}{|l|l|l|l|l|}
\hline Name & Sex & Age & Country of origin and language repertoire & Migrant status \\
\hline Andras & M & 37 & Hungary / Hungarian; English & spouse** \\
\hline Babak & M & 32 & Palestine / Arabic; French; English & asylum-seeker \\
\hline Carmen & F & 58 & Philippines / Tagalog; Wary-Wary; English; Spanish & spouse* \\
\hline Daria & F & 29 & Syria / Arabic; French; English & asylum-seeker \\
\hline Elena & F & 25 & Belarus / Russian; German; English & spouse* \\
\hline Firman & M & 29 & Iraq / Kurdish; Arabic; English & spouse** \\
\hline Galina & F & 48 & Ukraine / Russian; Ukraine; English & spouse* \\
\hline Hanna & F & 35 & Poland / Polish; Russian; German; English & spouse $^{* * *}$ \\
\hline Jasna & F & 51 & Serbia / Serbian; English & spouse $^{* *}$ \\
\hline
\end{tabular}




\begin{tabular}{|l|l|l|l|l|}
\hline Laura & F & 59 & Philippines / Tagalog; English & spouse $^{*}$ \\
\hline Mumtaz & F & 35 & Pakistan / Urdu; English & spouse $^{* * *}$ \\
\hline Najwa & F & 23 & Jordan / Arabic; French; English & spouse $^{* *}$ \\
\hline Safia & F & 33 & Syria / Arabic; French; English & asylum-seeker \\
\hline Visam & M & 31 & Lebanon / Arabic; French; English & spouse \\
\hline
\end{tabular}

Note:

* spouse of Swedish citizen

** spouse of Swedish citizen with migrant background

*** spouse of migrant worker

\section{Interviews}

During the winter/spring of 2013 two semi-structured interviews were carried out with each participant. ${ }^{\text {iv }}$ The longest interview lasted 56 minutes, the shortest 28 minutes. Interviews were structured around the following questions:

- What are the biggest challenges you face learning Swedish?

- What opportunities do you have to speak Swedish outside school?

- Do you find your knowledge of other languages helpful when learning Swedish?

- Do you find your knowledge of other languages helpful when communicating with Swedish people?

Follow-up questions in this study focused on participants' reports of making choices between English and Swedish, perceptions of the ways in which, in different situations, English could be experienced as a resource, and the nature of perceived advantages and disadvantages involved in speaking English. The interviews were carried out by the author, a speaker of both English and Swedish in the language (Swedish or English) chosen by the interviewee. Six of the participants chose to be interviewed in Swedish and six in English. One participant switched constantly between English and Swedish in both interviews, while another chose to have the first interview conducted in English and the second in Swedish. The interviews were audio-recorded and verbatim transcripts were made, resulting in a corpus of 76500 words. 


\section{Method of analysis}

Common to a number of qualitative approaches employed by researchers with an interest in multilinguals' language use and conceptions - e.g. Li’s (2011) Moment Analysis, Straub’s (2006) Interpretive Sequential Analysis (used by Samata 2014) and Smith’s (Smith, Flowers and Larkin 2009) Interpretive Phenomenological Analysis (used by Henry 2011) - is the understanding that the interview itself is a site of meaning-making engaged in by both researcher and participant. As participants piece together understandings of resource use, the researcher deploys theoretical knowledge in attempts to make sense of their articulations. This, as Smith and Osborn $(2008,51)$ explain, involves a form of “double hermeneutic”. As the participants try to make sense of their world, "the researcher is trying to make sense of the participants trying to make sense of their world”. This means that the researcher needs to adopt both an empathic and a critical standpoint (Smith and Osborn 2008). While the researcher needs to try to understand the situation as the participant sees it, there is also a need to step back and adopt a critical position, or, as Straub (2006) describes it, a need to move from working within the experiential space of the informant (the 'experiential horizon') into a more creative, analytical space (a 'counter horizon').

\section{Procedure}

To begin the process of “entering the participant’s world” (Smith, Flowers and Larkin 2009, 82) the transcripts were read through several times. ${ }^{\mathrm{v}}$ Thereafter comments, notes and annotations were made. The transcripts were then entered into NVivo 10.0 and read through again. This time cross-referencing between transcripts took place, shifting the whole time between discrete chunks of transcript and the emerging understanding of the dataset as a whole (Smith, Flowers and Larkin 2009). From this process a number of common themes emerged and were entered in NVivo as nodes. The transcripts were then reread several times, 
a process that involved assigning and reassigning transcript chunks to different nodes and revising/reformulating the nodes. Finally, a close analysis of each theme was carried out, deploying the theoretical concepts previously described.

\section{Presentation of data}

While Smith (2011) points to the importance of “gems” - relatively rare but particularly resonant utterances in the data which offer "potent analytical leverage to a study” (p. 6) Straub $(2006,187)$ emphasises a focus on "segments” from which “patterns of experience, expectation, meaning-formation, orientation, action and/or development can be extracted”. The analysis that follows is structured around three longer segments that offer insights into the attitudes, values, beliefs, social structures and discourses that impact on the language choices participants describe.

\section{Analysis}

This section begins with a brief description of situations where participants describe making choices between Swedish and English and continues with the analysis of segments of data that offer insights into these processes. First, employing Blommaert’s (2010) sensitizing concepts, focus is directed to the ways in which participants' reports reveal how evaluations of the exchangeability of the two languages impact on language choice, and how the choices they describe can be understood in the context of perceived evaluative authorities. Thereafter focus switches to the examination of agentic capacity. Drawing on Li's (2011) work, examination is made of participants’ critical appraisals and creative use of these language resources.

\section{Opportunities for speaking Swedish}


In line with other studies (e.g. Norton 2000, 2013), the current findings reveal that, with the exception of the women co-habiting with Swedish-born spouses, participants have very few contacts with Swedish-speakers outside of mundane daily transactions. ${ }^{\text {vi }}$ Asked about opportunities to speak Swedish other than in school Safia, for example, says "Not that much. When I buy something or... when I need something in the bus, something like that. Not that much because no... when I said I have big family here and we speak in Arabic all the time, so I don't use Swedish that much”. As well as family members, participants tell how friends and neighbours often speak the same language(s). As Najwa says, "I know just two or three women in Sweden. And they speak Arabic too”. Indeed only two arenas emerge where participants identify making choices about whether to speak Swedish or English; in encounters with agency officials (most frequently when visiting social insurance, employment and population registration offices), and in educational settings.

\section{Language choices in meetings with agency officials}

While participants report how, initially, encounters with agency officials took place in English or through the mediation of others, it emerges in the data that, over time, Swedish becomes a more natural choice. Jasna says that she now always begins meetings with agency officials in Swedish, even though she finds herself reverting to English after a while when she “can’t find the words”. Galina says that she started using Swedish when she realised that it better facilitated communication as some agency officials “didn’t speak such good English”. For Hanna the switch to using Swedish came rather suddenly:

...when my husband was unemployed and I needed to ask about something, ah, a man in the population registration office. I went to him and said to him: 'I can't speak in Swedish'. And then I started to speak. It was...I don’t know why. 
I think that, ah, always it was, ah...the other language. That I could use and I could find good words (interview in Swedish)

Because of the limited opportunities for interaction with Swedish-speakers, a number of participants frame encounters with agency officials as opportunities for learning, as for example Firman explains:

I...the reason why...If you want to speak the language well, you must use Swedish. You have to try more. If you want to have, to learn Swedish. Because. Because you must. (interview in Swedish)

Daria makes a similar point, saying the main reason she starts off with Swedish is to facilitate learning:

I have to speak Swedish to improve my, not to show that I can speak Swedish. I start to speak Swedish and when I forget something I start to, with English, when I in official things, when I go to the population registration office or the employment office. (interview in English)

As Daria indicates, when she remarks that her choice to speak Swedish is not about demonstrating competence, encounters with agency officials have an important appraisal function. It is in such situations that the migrant's 'integration' into society - i.e. fluency in the register of labour and education (Blommaert 2013) - is most closely evaluated, put to the test and judged, not just by the host state (through agency staff), but also by the individual. 


\section{The appraisal function of employment office interviews}

To more closely examine language choices in the context of these types of appraisal, focus is now directed to two longer data segments - passages that "prove extremely fertile to the research" and which "offer strong insight to the experience for this individual and often for the group of participants as a whole” (Smith 2011, 6) - first from an interview (in Swedish) with Visam and thereafter from an interview (in English) with Mumtaz:

I: Was it possible for you to speak Swedish in the beginning or did you have to use English to communicate, or?

Visam: Ah, yes, especially in those agencies...the employment office...the population registration office... but... but it is better that you speak Swedish, even if you speak bad Swedish. It is better.

I: $\quad$ Have you, in what way do you mean that it is better?

Visam: $\quad$...you are received better. Yes. Even if you speak bad Swedish.

I: Why do you think that is so?

Visam: It...maybe it depends on culture. It, culture plays a big role, a big role with culture. But...maybe xenophobia too. Hmm...

I: $\quad$ Yes, it can be so, yes...

Visam: Yes, it is also here in Sweden ahh...quite.... lot of people are xeno- xenoxenophobic. So it is better to use Swedish.

I: Why do you think it is better to use Swedish? I am interested in what you say. Could you say a bit more about it? 
Visam: Aah because they, because they feel a little comfortable. When you speak Swedish with them. Hmm better than communicating in English. Because they maybe feel that you are trying to integrate here.

I: $\quad$ Hmm. And you've noticed this. And has it, when you noticed this, influenced you? Like 'no, I’ll use Swedish and not use...

Visam: Yes, very much so

I: $\quad$ OK

Visam: It played a big, a big role

I: $\quad$ OK

Visam: $\quad$ And I have discovered that you need to learn the language to integrate here.

I: $\quad$ Compared to when we last spoke, is English as much of a help as it was then or less of a help now?

Mumtaz: No, English always helps me, I think. Because still now I can say if I don't feel myself to explain in Swedish, err, there are many places where they don't have the time to listen to our Swedish, like I'm not perfect, so it's better to direct talk in English so the other authorities they also become glad and I think they talk more nicely when you speak English. Yes, I think some people they appreciate if you can, they appreciate if you speak English than you speak broken Swedish.

I: Is there kind of a strategy, 'OK, so I'm going to arbetsförmedlingen [the employment office] I'll speak English' or is it more like 'well, it depends who I'm speaking to and I might use English if I don't think the communication is going that well'? 
Mumtaz: It depends on what you're going to ask. If you're going to ask some serious or important so and if I start speak Swedish so I know what I’m asking so I will...I will ask right Swedish. I will speak right Swedish in my question. But when they will answer me so they told 'oh, she can speak good Swedish' so because I ask the question in right Swedish so they will answer me like...I can understand what they told maybe, I think I understand all, but I'm not satisfied with the answer. So what I will do? I will ‘oh no, please repeat, I can’t speak Swedish’? So it's better to say this than waste their time so...it's very important to get the right answer. So you can speak Swedish...you can speak English [self correction] and get answer in English. So it will be easy for them and you as well. But now when I go to arbetsförmedlingen [employment office] or I know I don’t have to ask so important question so I just need my schema [schedule] for my attendance so I mostly speak Swedish now.

Visam emphasises the importance of speaking Swedish in encounters with agency officials, even if communication can only take place at a basic level. The reason, he says, is to secure a positive initial reception (“...you are received better”). Encouraged to develop this line of thought, he goes on to identify four separate yet interlinked beliefs underpinning this choice. First he points to normative expectations (“culture plays a big role, a big role with culture”), and, continuing, the sense of a need to pre-empt the risk of negative consequences flowing from communicating in English should his interlocutor have negative views about migrants (“quite...a lot of people are xeno- xeno- xenophobic”). Given the opportunity to further expand on the rationale for this choice he identifies two additional beliefs. It is, Visam says, important that his interlocutor should feel comfortable in meeting a person from a different cultural background (“Aah because they, because they feel a little comfortable. When you speak Swedish with them”). Finally he identifies an advantage of using Swedish as it signals a desire to integrate ("Hmm better than communicating in English. Because they maybe feel that you are trying to integrate here”). In making these choices the influence of the projected 
presence of an evaluative authority appears evident; "they maybe feel that you are trying to integrate...”. It is not just immediate addressees - the employment consultants - to whom ‘they’ refers, and in relation to whom resource selections are made. Speech acts are also, in Blommaert's (2010) terms, directed towards a projected evaluative 'centre’.

Interpreting these choices, Swedish functions as an optimal resource at different scale levels. In Blommaert's (2010) theorising space is stratified and "power-invested” (34), scale levels functioning as a device to capture multiple layers of context. At the micro-level Visam makes the assessment that Swedish facilitates ongoing transactions, buffers against possible Othering, and reduces risks of a prejudice-tainted response. Moreover, it signals flexibility, adaptability and, not least, employability; qualities likely to be positively evaluated by interlocutors in situations where support from state agencies is sought. Viewed at a macrolevel, Swedish also functions as an optimal resource; in the context of discourses of immigration where language is positioned as “decisive” there are powerful normative expectations that migrants seeking to establish themselves should to be able to communicate in Swedish. Behaving in ways that challenge such norms, particularly in an employment office setting, are likely to have consequences. Migrants are expected to be fluent in the registers of education and labour. They are expected to be 'fully' integrated into niches society deems appropriate and, should they fail to meet these expectations, they risk becoming perpetually regarded as “dis-citizens” Blommaert $(2013,3)$. Thus the employment office interview becomes a critical site where identities - the 'citizen in-the-making', employable through fluency in the register of labour, and the 'good migrant' who recognises that Swedish provides the springboard to integration - are perfomatively enacted. 
At the same time Visam's reflections also demonstrate criticality, in his evaluation of the situation, and creativity in actively making the decision to conform to the perceived expectations of interlocutors, especially when, linguistically, this is likely to involve a further tipping of the scales in what already is a highly asymmetrical relationship (Visam, who has been in Sweden for seven months, explaining how he feels more competent in English and how he has to constantly force himself to rely less on English (see Henry, in review)). In providing a complex and sophisticated analysis of the social and linguistic practices he experiences in transactions with agency officials, Visam's response reveals not only an active choice to behave in a manner congruent with expectations of a projected evaluative authority (Blommaert 2010), but also an awareness of the present conditions in which he finds himself and the capability to carry out assessments of the exchangeability of language resources - the manifestation of criticality - and to make choices about language use (i.e. whether or not to conform to normative expectations) constituting thus the exercise of creativity (Li 2011).

In the types of interaction that take place in state agency offices, the English used by Mumtaz (a language that, in Pakistan, young people from the middle classes acquire from an early age through education) and by Visam (who says he attended French-speaking schools and that his English has mostly been acquired through accessing English-language Internet sites), is likely to have a different value. Pointing to the existence of orders of indexicality, Blommaert (2010) describes how languages are marketable commodities in "an economy of exchange” where "the values attached by some to one form of semiosis may not be granted by others" (38). In the situations currently in focus, the potential exchangeability of English and Swedish may, for these two migrants, be very different. While in a Swedish context of high levels of communicative competence in English, Mumtaz's self-confident, fluent and lexically sophisticated English can signal an educated, middle-class background - constituting, in the 
employment office setting, a valuable resource - the English that Visam speaks may not generate similar capital. In this economy of exchange Visam's English is afforded a different value.

Rationalising her language choices, evidence of criticality can be seen when Mumtaz talks of how she makes assessments of situations when in contact with state agencies and, depending on the nature of the visit - whether it is an "important" or "serious" question or simply to get a "schedule" - deciding whether to speak Swedish or English. We see also creativity in the sense that, unlike Visam, Mumtaz talks in ways that evidence a sense of experiencing a greater freedom in being able to actively decide which language to use in different situations; “...if I don’t feel myself to explain in Swedish”. This in turn links to her identity. Mumtaz’s husband is in skilled employment. She has a degree in business administration and in our interviews talks of plans to continue her education in Sweden at the Masters level, her longterm goal to obtain suitable professional employment. Visam, on the other hand, is reliant on benefits. His wife (also a migrant from Lebanon) is unemployed. Working previously in TV production, his goal is to gain employment of any kind (he has no preferences and, at the time of the interviews, was considering moving to the north of Sweden to get a job in an iron ore mine). Thus for Mumtaz, because the power dynamic in meetings with employment office officials is less asymmetric (not only in material terms, but also as she perceives it), this means that she experiences greater flexibility in being able to move between Swedish and English and a greater scope for creativity in her choices (Swedish for run-of-the-mill transactions and English for important things).

Finally, Mumtaz’s choices to speak English when discussions revolve around issues of importance can also be understood in terms of identity investment (Norton 2000, 2013). As 
recounted by Norton in her seminal study of migrant women in Canada, several informants, particularly those with academic backgrounds, were uncomfortable speaking English because doing so positioned them as immigrants. Thus Mumtaz's choice not to use Swedish other than for everyday dealings can be understood as a form of identity-protection. Similarly to one of the women Norton interviewed who was reluctant to speak English because she felt uncomfortable communicating with native speakers, telling how "some Canadians are fed up with people who are not able to communicate well in English” (Norton 2013, 92)), Mumtaz makes the point that in Sweden it is better to speak English, as “there are many places where they don’t have the time to listen to our Swedish”.

\section{Resource selection in the classroom}

The other arena where participants talk about the exchangeability of Swedish and English is in educational settings. Although language and social orientation courses are taught entirely in Swedish, given the cultural and linguistic heterogeneity of the learner groups, in social interaction taking place both in and outside of the classroom, for some participants English can function as a more effective lingua franca.

Some participants say that they feel they have achieved a level of competence where they rarely use any English. As Elena explains, when communicative problems arise she bides her time, using English as a source of lexical support rather than switching to English:

I take it easy. I know that I can speak Swedish quite fluently. So in my language right now there are lots of 'oh', 'err' and such. But I, I try to remember and take a few risks in English and all the languages I know. (interview in Swedish) 
However, for many others, English is used frequently in social interaction. As Galina observes, “many of the participants here use English”. Andras says that "sometimes I speak Swedish sometimes and sometimes English”, while Laura says that social interaction with her classmates is mainly in English, except with those who she doesn't judge to be very good and with whom she says "I slowly have to mingle with them in Swedish".

Participants also talk about the ways in which English is a part of the classroom environment, functioning as a channel for metacommunication (see Henry, in review). Babak, for example, talks about how he uses English to ask teachers and other students to explain things for him, while Hanna and Galina both talk about how they ask the teacher to explain new vocabulary in English.

\section{Self-governance in monolingually-oriented learning practices}

As with the previous section, focus is now directed to a longer data segment particularly illustrative of the way in which language choices can be understood as made with reference to evaluative authorities (Blommaert 2010), and as revealing manifestations of agency in the form of criticality and creativity (Li 2011):

Daria: $\quad$ No, we don’t use English with each other, never. We put like a rule, even in [name of school] we had friends from America and...Storbrittanien [Great Britain] but we make a deal. We will not speak English during class.

I: $\quad$ Can you tell me about that? Tell me more about that? How did that happen?

Daria: $\quad$ That happened because we speak all the time...as...as... as I told you...we speak all the time English. Even, we don't have many... when we start we didn’t have words to...express ourselves...that's why we...it's easy to speak in 
English...we...err...we change [laughs]...so we after for...for looking for ... find the words in English, we made a deal, we should just speak Swedish, even if it was horrible or any, or bad, or...we make... all the students...um...older than us, made a paper on the wall..."bara svenska” [Only Swedish] in Swedish...

I: $\quad$ Right, and that was even the students who spoke English as a mother, as their own language from the UK and from the USA

Daria $\quad$ Yes, yes

I: $\quad$ and Pakistan, where there’s lot of English? But everyone said “only Swedish”?

Daria: Only Swedish. We break this rule [laughs]

I: $\quad$ You break this rule?

Daria [laughing] Yes, yes.

I: When does that rule get broken? When does that happen?

Daria: Umm... $\quad$ when we do, we work hard [laughs] first five or ten minutes when we had subject or something. We work hard for ten minutes and after that we say; 'Enough. [laughs] We will err we will have fun'...

Like many migrants to Sweden, Daria (interviewed in English) finds herself in educational environments populated by students from all corners of the globe. In these super-diverse classrooms lingua francas have important social functions. However, as Rosén and BaggaGupta (in press) have shown, in some classrooms monolingual norms prevail. In such classrooms teachers "orient towards an interaction order where the usage of language varieties other than Swedish is considered illegitimate”. For these teachers the exclusive use of Swedish is seen as essential for achieving the goal of learning the target language, the authors 
describing how teachers and students together create monolingual interaction orders where Swedish becomes the only legitimate language for classroom communication.

In telling how she and her classmates attempt to establish a Swedish-only environment, Daria's words reveal the operation of polycentricity (Blommaert 2010). In trying to stick to Swedish, Daria and the others behave with reference not just to teachers' expectations and preferences, but also to a superordinate evaluative authority; the Swedish state as provider of education, enactor of language policy and evaluator of the migrant's willingness, preparedness and ability to act in conformity with ideal-types of norms. Within these structures of power the positioning of themselves as 'good migrants' requires the use of ‘appropriate’ resources.

However, as Daria makes clear - and is graphically testified to by the decision of a previous group of students to attach an "only Swedish” poster to the classroom wall - the use of Swedish as a medium of communication is not always self-evident. Nor is it always desirable. Self-monitoring and circumspection are therefore constantly required. Such continual selfmonitoring can, in Foucault's terms, be understood as form of self-governance or a 'surveillance of the self'. It is a discipline, Taylor (2010) reminds us, that “precedes us and comes from the outside, not from a decision of one’s own”. In contemporary society voluntary submission to the surveillance of another does not spring directly from a desire to monitor ourselves. Rather, as Taylor (2010) explains, “we first find ourselves monitored, without having chosen to be, and then we internalize this surveillance” (198).

Even though it would appear that Daria and the other students have internalized the surveillance of the evaluative authority of the Swedish state - present in the "monolingual 
orientation” (Canagarajah 2013, 19) of an educational system designed to achieve the speedy integration of migrants, in teachers' monolingually-oriented professional practices, and in the classroom's monolingual interaction order (Rosén and Bagga-Gupta in press) - it is also important to recognise that individuals have agentic capacity for self-determination and the ability to challenge and resist structures of domination (Besley 2007; Blommaert 2010; Canagarajah 2013). Thus while choices to use Swedish as the medium of communication in the classroom - “we should just speak Swedish” - can be understood as a consequence of processes involving the self-surveillance of conduct and a manifestation of a "care for the self” (Taylor 2010), shifts to English demonstrate resistance. Deviations from the "only Swedish” rule become challenges to internalised practices that have been externally imposed. In acting in ways that go against the grain of a jointly-constructed monolingual practice and risk undermining processes in which students position themselves as 'good migrants', the communication practices Daria describes reveal both criticality and creativity. As multilingual speakers they are, as $\mathrm{Li}(2011,1234)$ explains, “not simply responding, rationally or not, to broader social forces and structures, but are creating spaces for themselves using the resources they have”. Similarly to the students in Mortensen’s (2014) study of language use in an institutionally-imposed ‘English only’ educational environment in a Danish university, the students in Daria's class are, in this semiotic space, creatively developing their own language practices suitable for their particular communicative needs.

\section{Discussion}

\section{The performative enactment of identity options in institutional settings}

In the analysis of the data it emerges that in institutional settings Swedish is the favoured language choice for a number of the recently arrived migrants interviewed here. Many of these participants are highly motivated to learn Swedish and emphasise the importance of making the most of the limited opportunities they have for using Swedish outside the 
classroom. Given disparities in levels of communicative competence (many of the migrants recognising, like Visam, that they are more proficient in English), the near ubiquitous presence of English in Swedish society (Cabau 2009) and Swedish-speakers’ positive attitudes to English, high levels of communicative competence and general willingness to speak English with recently arrived migrants (Bolton and Meirkord 2013; see also Henry in review), this preference might appear somewhat surprising. However, as the analyses reveal, in institutional environments language choices are made in contexts of a projected presence of evaluative authorities and involve processes of self-surveillance. Interviews with agency officials and social interaction in school settings become sites where identity options are performatively enacted, the use of Swedish signalling flexibility, adaptability and a desire to 'integrate’ into Swedish society. These forms of identity performance are particularly important for migrants for whom, like Visam, institutional encounters involve power dynamics that are highly asymmetric and where failure to meet the expectations of others involves the risk of an enduring marginalization. In the context of such interactions, the relative exchangeability of the two languages differs; some varieties of English (for example that spoken by Visam) are not as highly valued as others (such as that spoken by Mumtaz). Consequently perceptions of having opportunities to use English in facilitating communication can differ dramatically. This means that while for some migrants English constitutes a highly valuable resource, for others it may not offer a viable communication option.

\section{Displaying solidarity with monolingual norms in communicative performance}

In responding to global flows of people and languages, Western democracies have tended to unite around the hegemony of majority languages (Hymes 1996). Monolingual norms (Blommaert 2010) and orientations (Canagarajah 2013) are generally espoused and dominant 
ideologies of monolinguistic homogeneity are produced and reproduced (Heller 1999). Such moves, as Blommaert (2010) makes clear, represent classically modernist responses to migration. Faced with the effects of super-diversity, Western governments, he argues, quickly return "to the safe fortresses of modernism, emphasizing homogeneity and uniformity across the population” (173).

While in Sweden approaches to migration are by tradition liberal and ethnic diversity has steadily increased (Brochmann and Hagelund 2011a, 2011b), language policy nevertheless espouses monolingual norms. The recent Language Act (Ministry of Culture 2009) provides a clear example of what in Canagarajah's $(2013,19)$ terms is the embodiment of a “monolingual orientation”. While recognising that "everyone has the right to language”, the Act nevertheless plays down the role of multilingual communication, emphasising instead a need to "safeguard the country’s main language as a complete language, serving and uniting society” (Ministry of Culture 2009). In positioning the use of languages other than Swedish as a threat, its unambiguous objective, as Boyd (2011) observes, is "to hold back the spread of English” (26).

In such a climate the use of English can therefore be additionally problematic. Not only in the envisioned scrutiny of evaluative authorities can the use of English signal a lack of interest in 'integrating' and a deviation from the language practices of 'good' migrants (Blommaert (2010, 2013), in the context of dominant monolingual ideologies and political discourses upholding the primacy of Swedish, the use of English can be interpreted as a challenge to the status and vitality of Swedish and a threat to its status as the "main" and "common" language in Sweden. 
However, in the same way that perceptions relating to the exchangeability of language resources differ between speakers, so too do perceptions of the need to display solidarity in communicative performance by speaking the "common language”. These perceptions are embedded in discursive positionings associated not only with the geopolitical realities of migrants' countries of origin, but also with their socioeconomic status, gender, educational attainment and social/professional aspirations. Consequently the sense in which the use of English might be perceived as a threat to the monolinguistic homogeneity (Heller 1999) may differ depending on the ways in which, in institutional settings, identities are negotiated, and the ways in which migrants position themselves and are positioned by others (Pavlenko and Blackledge 2004).

\section{Intersections of discursive positionings}

In addition to the perception of a need to behave in a manner congruent with the expectations of a projected evaluative authority and, performatively, to position himself as a 'good migrant' possessing 'a desire to integrate', Visam, as previously discussed, is also aware of a general presence of xenophobia. From a region that, as a consequence of the media reporting of violence spilling over from the Syrian civil war concurrent with his arrival, is linked with unrest and instability, the use of English can serve to accentuate associations with a refugee status. Given that Visam's move to Sweden is in the context of a transnational spousal relationship, these are geopolitical associations he may wish to avoid. At the same time he may also be associated with the Lebanese diaspora. Large numbers of Lebanese nationals and Palestinians domiciled in Lebanon migrated to Sweden in the 1970s and 1980s, many of these migrants and their families now well-established in Swedish society. In this light, communicating in English could also involve a negative positioning, i.e. as someone who, unlike others from similar ethnic/national groups, has failed to attain language skills otherwise 
widely possessed. Further, choosing English could function as an identity-marker of an individual adopting the position that English alone is adequate to get by with in Sweden; a deliberate act of self-distancing from an imagined community of speakers of the country's “main language” (Rosén and Bagga-Gupta in press; Blommaert 2010). Anxious to avoid these disconnects, Swedish provides Visam with a more viable resource option. It functions in multiple ways that can allay a range of possible prejudices possessed by powerful others, prejudices he knows can lead to inequitable treatment.

Mumtaz, in contrast, does not belong to an ethnic group with a history of migration to Sweden. Nor does she come from a part of the world most immediately associated with unrest or violence. In the new patterns of transmigration currently emerging as a consequence of globalization (Held et al. 1999; Vertovec 2007) Mumtaz, the university-educated wife of a geographically-mobile service-sector professional, is the epitome of the cosmopolitan citizen. For her, decisions to speak English are far less likely to generate the types of negative association were Visam to make similar choices. Nor, in orienting towards the evaluative authority of the superimposed addressee (the Swedish state), does her choice in the employment office signal subversion or a potential undermining of the host country's “common language”. Although in Bauman’s (1998) terms Mumtaz might not be considered one of the privileged elite of globetrotting "wanderers" or "tourists" who consume other places, her opportunities for mobility (her husband's job provides international employment possibilities and the family lived in another EU country before moving to Sweden) mean that, vis-à-vis the super-addressee, her use of English does not constitute a threat to social cohesion. This can be contrasted with the situation for asylum-seekers or their spouses (“vagabonds” in Bauman's framing). For such people, a lack of alternatives implies that migration is more likely to be permanent, meaning that a similar choice could trigger very 
different positionings in relation to ideological subjectivities; the "lazy immigrant" or “dependent foreigner” as opposed to “responsible citizen” (Canagarajah 2004, 267).

Differences in perceptions of the need to performatively display solidarity by speaking the “common language” are found not only when the reflections of Visam and Mumtaz are compared; differences in other participants’ perceptions are also observed. As we have seen, Firman and Daria both frame encounters with agency officials as opportunities for practicing Swedish. While Firman is adamant that speaking Swedish is the only option, Daria makes clear that speaking Swedish is not about demonstrating competence (i.e. positioning herself as a 'good' migrant), and that she readily switches to English. This suggests a need to develop awareness that migrants’ perceptions of the exchangability of Swedish and English are not just a consequence of positionings based on geopolitical spaces of origin, but also of intersections with other discursive positionings. Rather, it is the combination of various positionings (associated with migrant status, geopolitical spaces of origin, ethnic group, educational backgrounds, articulated aspirations and gender) that impact on language choices. Thus, even though Daria comes from a similar geopolitical space as Visam and Firman (she from Syria, they from Lebanon and Iraq), the variety of English she speaks having an ostensibly similar value, the intersection of other positionings mean that, for Daria, English is a viable communicative option. Daria’s aspirations are markedly different from Visam’s (who says he would gladly take any job) and even Firman (who wants to continue a career in engineering). Because her aim is use her language skills in professional employment as a translator or language teacher, her use of English becomes legitimate in that it positions her as a language professional. Gender too plays a role. As Eid (2014) has shown, while in Western media people from Muslim countries are represented generally as intolerant, anti-democratic and violent, Muslim women tend to be represented as passive and oppressed. Consequently, 
in contact with agency officials, and in the presence of a projected super-addressee, while for Visam and Firman intersections of discursive positionings make the use of English problematic, for Daria a different constellation of positionings serves to legitimise her use of the language.

Let us turn now to consider the power dynamics at play in the educational setting Daria describes. As we have seen from the self-surveillance practices she tells about, a monolingual norm seems to prevail, meaning that the classroom use of language resources other than Swedish could constitute transgressive behaviour. While, on the face of things, normbreaching shifts to English can be understood as a form of resistance - a collective protest against the (self)imposition of the "only Swedish” rule - it is important to note that shifts to English seem to take place in controlled circumstances. Specifically, Daria explains how she and her classmates speak English only after they "work hard for ten minutes”. That is to say, the exchange of resources occurs only once norm-conformist credentials have been established. Functioning as a reward, and because English is used playfully, the switch is legitimised. Used in this way it does not pose a threat to the monolingual norm.

There is however another sense in which the breaching of the monolingual norm may not be as transgressional as might first appear. In the group in which Daria works there are a number of students who have spoken English from birth or an early age. Thus, even in the climate of monolingual norm-conformity and self-surveillance, the use of English can appear as more legitimate and less threatening than were a group of exclusively EFL speakers to switch to lingua franca English. Seen this way, we can again understand how the potential for the exchangeability of Swedish and English differs depending on the intersections of discursive 
positionings, English being a highly exchangeable commodity when, as in the current instance, privileged speakers (here from the UK and US) are parties in the interaction.

\section{Conclusion}

In line with previous research, the results of the current study highlight the segregated nature of contemporary societies, the migrants here talking of a paucity of contacts with speakers of Swedish. Two contexts are identified where participants (other than those cohabiting with Swedish men) describe having the option to speak either Swedish or English; in encounters with state agency officials and in educational settings. Applying Blommaert’s (2010) sensitizing concepts of polycentricity and orders of indexicality, the aim has been to show how the Swedish/English language choices participants describe reveal ways in which resource deployment takes place in hierarchical systems of value that have consequences for exchangeability. In so doing these processes of selection have been set in a broader context of power dynamics which reveals how language choices are embedded in questions of discursive positionings and the geopolitical circumstances in countries of origin. The analyses also shed light on individual agency and the participants' creative and critical capacities (Li 2011), revealed in the ways that, in their language choices, the participants evaluate, relate to and resist macro-social structures.

In the light of these findings Bolton and Meirkord's (2013) contention that migrants with English in their repertoires appear to "rely on the language as a lingua franca during the early part of their stay in Sweden” (105) may require a degree of qualification. For many of the current participants Arabic functions an optimal resource in social interaction (not least in local communities). Furthermore, digitalization means that 'immigrant languages' are widely encountered in various social spaces and language brokers play important roles in mediating 
communication (Cline et al. 2011). While for some English-speaking migrants English does indeed function as an effective lingua franca in their initial period in Sweden, this may not be the case for everyone, or in every situation. On the contrary, the current results suggest that the landscape of language opportunities forms decidedly uneven terrain. While for large sections of the population, including many migrants, English has a functional value in a range of social and societal domains, generating cultural capital and connoting liberal, educated and cosmopolitan backgrounds and values, this is not the case for everybody. As suggested here, different varieties of English offer different opportunities and not all varieties are equally exchangeable. For some asylum-seeking migrants and the relatives/spouses who join them, the English they speak may not have a particularly high value. Inequalities in exchangeability are, as Blommaert (2010) reminds us, not about languages. As the current analyses reveal, opportunities to use English differ not just in relation to the variety spoken, but also in relation to modes of use and as a consequence of the intersections of different discursive positionings.

The language practices and choices made by English-speaking migrants to countries where English has a lingua franca function have so far received little attention in the research literature. Given continued transnational migration, the continuing spread of English across the globe and modernist/neoliberal-influenced measures directed towards migrants' early attainment of skills in the host country's 'main language', it is an area likely to be of increasing interest. In addition to ethnographic research focusing on the situated use of the full range of migrants' language resources in the types of public settings investigated here, research also needs to be directed to the ways in which, in their professional practice, education and state agency staff can facilitate or hinder opportunities for the effective use of such resources. It is only once we begin to understand the effects that social contexts and language policy have on migrants' opportunities to deploy the full range of their resources 
that we will be in a position to develop practice approaches that recognize and properly value multilingual migrants’ multi-competence.

\section{Acknowledgments}

I would like to thank the anonymous reviewers of this paper for the many important insights they have offered and Susan Samata for introducing me to the work of Jurgen Straub.

\section{References}

Bauman, Z. 1998. Globalization: The Human Consequences. Cambridge: Polity Press.

Besley, A.C. 2007. Foucault, truth-telling and technologies of the self: Confessional practices of the self and schools. In Why Foucault? New directions in educational research, ed. M. A. Peters \& A. C. Besley, 55-70. New York: Peter Lang.

Björklund, J., M. Arnholm and E. Ullenhag. 2013. Svenska för invandare måste förändras i grunden [Swedish for immigrants must be changed from the base]. Dagens Nyheter 31 January.

Blommaert, J. 2010. The sociolinguistics of globalization. Cambridge: Cambridge University Press.

Blommaert, J. 2013. Citizenship, language and superdiversity: Towards complexity. Tilburg Papers in Culture Studies 45 1-4.

Bolton, K. and C. Meirkord. 2013. English in contemporary Sweden: Perceptions, policies, and narrated practices. Journal of Sociolinguistics 17: 93-117.

Boyd, S. 2011. Do national languages need support and protection in legislation? The case of Swedish as the 'principal language' of Sweden. In Uniformity and diversity in language policy: Global Perspectives, ed. C. Norrby and J. Hajek. 22-36. Bristol: Multilingual Matters. 
Brochmann G. and A. Hagelund. 2011a. Migrants in the Scandinavian Welfare State. Nordic Journal of Migration Research 1: 13-24.

Brochmann G. and A. Hagelund. 2011b. Immigration policy and the Scandinavian welfare state 1945-2010. Houndmills: Palgrave Macmillan.

Butler, J. 1990. Gender Trouble: Feminism and the subversion of Identity. New York: Routledge.

Cabau, B. 2009. The irresistible rise and hegemony of a linguistic fortress: English teaching in Sweden. International Multilingual Research Journal 3: 134-152.

Canagarajah, S. 2004. Multilingual writers and the struggle for voice in academic discourse. In Negotiation of identities in multilingual contexts, ed. A. Pavlenko and A. Blackledge. 266-289. Clevedon: Multilingual Matters.

Canagarajah, S. 2013. Translingual practice: Global English and Cosmopolitan Relations. New York: Routledge.

Cline, T., Crafter, S., O'Dell, L. \& de Abreu, G. 2011. Young people's representations of language brokering, Journal of Multilingual and Multicultural Development, 32 (3): 207220.

Eid, M. 2014. Perceptions about Muslims in Western societies. In Re-imagining the Other: Culture, media and Western-Muslim intersections. ed. M. Eid and K.H. Karim. 99-120. New York: Palgrave Macmillan.

Garcia, O. and Li, W. 2014. Translanguaing: Language, bilingualism and education. Houndmills: Palgrave Macmillan.

Harré, R. and van Langenhove, L. 1999. Positioning theory: Moral contexts of intentional action. Oxford: Blackwell. 
Harissi, M., Otsuji, E. and Pennycook, A. 2012. The performative fixing and unfixing of subjectivities. Applied Linguistics 33 (5): 524-543.

Held, D., McGrew, A., Goldblatt, D., and Perraton, J. 1999. Global Transformations: Politics, economics and culture. Cambridge: Polity Press.

Heller, M. 1999. Linguistic minorities and modernity: A sociolinguistic ethnography. London: Longman.

Henry, A. 2011. Examining the impact of L2 English on L3 selves: A case study. International Journal of Multilingualism 8: 235-255.

Henry, A. in review. Enablements and constraints: Inventorying affordances associated with lingua franca English. International Journal of Bilingual Education and Bilingualism.

Hymes, D. 1996. Ethnography, linguistics, narrative inequality: Toward an understanding of voice. London: Taylor \& Francis.

Lewis, G., B. Jones, and C. Baker. 2012. Translanguaging: origins and development from school to street and beyond. Educational Research and Evaluation: An International Journal on Theory and Practice, 18: 64 -654.

Li, W. 2011. Moment Analysis and translanguaging space: Discursive construction of identities by multilingual Chinese youth in Britain. Journal of Pragmatics 43: 1222-35.

Li, W. and Z. Hua. 2013. Translanguaging identities and ideologies: Creating transnational space through flexible multilingual practices amongst Chinese university students in the UK. Applied Linguistics 34: 516-535.

Ministry of Culture. 2009. Language for All. Summary of Swedish Government Bill 2008/09:153.

Møller J.S. and Jørgensen N. 2012. Enregisterment among adolescents in superdiverse Copenhagen. Tilburg Papers in Culture Studies 28 1- 15. 
Mortensen, J. 2014. Language policy from below: language choice in student project groups in a multilingual university setting. Journal of Multilingual and Multicultural Development, 35: 425-442.

Norton, B. 2000. Identity and language learning: Gender, ethnicity and educational change. Harlow: Pearson Education

Norton, B. 2013. Identity and language learning: Extending the conversation. Bristol: Multilingual Matters.

Rosén, J. and S. Bagga-Gupta. 2013. Shifting identity positions in the development of language education for immigrants: an analysis of discourses associated with 'Swedish for immigrants'. Language, Culture and Curriculum, 26: 68-88.

Rosén, J. and S. Bagga-Gupta. In press. Prata svenska, vi är i Sverige! [Talk Swedish, we are in Sweden!] A study of practiced language policy in adult language learning. Linguistics and Education.

Pavlenko, A. and Blackledge, A. 2004. Introduction: New theoretical approaches to the study of negotiation of identities in multilingual contexts. In Negotiation of identities in multilingual contexts, ed. A. Pavlenko and A. Blackledge. 1-33. Clevedon: Multilingual Matters.

Pennycook, A. 2003. Global Englishes, Rip Slyme and performativity. Journal of Sociolinguistics 7 (4). 513-533.

Pennycook, A. 2010. Language as a local practice. Oxford: Routledge.

Samata, S. 2014. The cultural memory of language. London: Bloomsbury.

Smith J.A. 2011. We could be diving for pearls: the value of the gem in experiential qualitative psychology. Qualitative Methods in Psychology Bulletin 12: 6-15 
Smith, J.A., P. Flowers and M. Larkin. 2009. Interpretive phenomenological analysis.

London: Sage.

Smith, J. A. and M. Osborn. 2008. Interpretative phenomenological analysis. In Qualitative Psychology, 2nd ed. ed. J. A. Smith, 53-80. London: Sage.

Straub, J. 2006. Understanding cultural differences: Relational hermeneutics and comparative analysis in cultural psychology. In Pursuit of meaning: Advances in cross-cultural psychology ed. J. Straub, D. Weidemann, C. Kolbl, and B. Zielke, 163-214. Bielfeld: Transcript Verlag.

Taylor, C. 2010. The culture of confession from Augustine to Foucault: A geneaology of the 'Confessing Animal’. London: Routledge.

Vertovec, S. 2007. Super-diversity and its implications. Ethnic and Racial Studies, 30: 10241054.

\footnotetext{
i In the European Commission's Survey on Language Competences (European Commission, 2012) more 14-15 year-old students in Sweden than any other country were assessed to be in the CEF B2 'upper intermediate user' category for reading and listening. In a survey carried out by language education provider EF, Swedish participants were ranked first among 54 participating countries.

ii In the 2005 Eurobarometer, Europeans and their Languages (European Commission 2005), in response to the question 'do you think knowing other languages than your mother tongue is, or could be very useful for you personally?, Sweden topped the list of countries with $99 \%$ of respondents expressing agreement. When asked which language was most important, 97\% said English.

iii Gauged as around or above the midpoint on a line ranging from 'only basic phrases' to 'like a native speaker'.

iv Three participants (Babak, Galina and Safia) were interviewed once due to leaving the program and illness.

v Because the aim of interpretive analyses is to make sense of the content of participants' accounts, a detailed transcription of prosodic aspects of recordings is not required.Transcripts generally include notes rather than coded representations of notable non-verbal utterances such as laughter and significant pauses (Smith, Flowers \& Larkin, 2009, p. 74). Here significant pauses are indicated by ellipses (...). Laughter and self-correction are noted in square brackets. Reported speech is presented in single quotation marks. When participants use the Swedish names of institutions in interviews in English, a translation is provided.

${ }^{\text {vi }}$ It should be noted that workplace practice periods had not begun at the time most interviews took place.
} 